\title{
Effect of pilocarpine on visual acuity and on the dimensions of the cornea and anterior chamber
}

\author{
D. POINOOSAWMY, S. NAGASUBRAMANIAN, AND N. A. P. BROWN \\ From the Department of Experimental Ophthalmology, Institute of Ophthalmology, London
}

There are many data on the effect of pilocarpine on the anterior chamber, particularly in respect to reduction in intraocular pressure and in anterior chamber depth and miosis, but the effect of pilocarpine on the anterior chamber volume and corneal curvature has not previously been studied. Pilocarpine commonly causes reduced visual acuity which may be partly due to miosis, but in this study reduced visual acuity is shown to be mainly due to a myopic change. The mechanism of the myopic change has not previously been established and it is now shown to be caused by changes in radius of curvature of the lens, similar to changes occurring in accommodation; changes in radius of curvature of the cornea are relatively unimportant.

Pilocarpine reduces the anterior chamber depth (Heim, I94I ; Rosengren, 1950; Törnqvist, 1956; Bleeker, I960; Romano, I968; Wilkie, Drance, and Schulzer, 1969; Poinoosawmy and Roth, 1974). This effect is probably related to an increase in the sagittal width of the lens as demonstrated by ultrasound (Abramson, 1972; Abramson, Coleman; Forbes, and Franzen, 1972) and is not connected with the reduction in intraocular pressure. In this study the reduction in anterior chamber depth is correlated with the reduction in anterior chamber volume and in the radius of curvature of the lens; these have not hitherto been reported.

Miosis may result in better visual acuity in some patients who are initially ametropic, but reduced visual acuity is the more usual effect of pilocarpine. Visual acuity has been shown to improve if the pupil diameter is reduced to $2.5 \mathrm{~mm}$ (Hallden, 1973a and b) and to deteriorate with further reduction below this figure; this deterioration is believed to be due to diffraction. The current study shows that changes in visual acuity result from factors unrelated to miosis.

An increased radius of curvature of the cornea has been shown to occur with a rise in intraocular pressure (Poinoosawmy and Roth, 1974). Reduction in corneal radius is therefore to be anticipated with

Address for reprints: D. Poinoosawmy, Department of Experimental Ophthalmology, Institute of Ophthalmology, Judd Street, London WCIH 9 QS the reduction in intraocular pressure resulting from pilocarpine, but this has not previously been measured. The present study investigates the effect of pilocarpine on the cornea with pachometry and keratometry.

\section{Materials and methods}

\section{SELECTION OF SUBJECTS}

Altogether 105 patients of both sexes were selected. They ranged in age from 35 to 70 years and included normal subjects as well as patients with confirmed narrow-angle and chronic simple glaucomas. In all 180 eyes were studied.

\section{Methods}

In those patients already receiving pilocarpine, the drug was withdrawn for at least 24 hours before beginning the study. The following parameters were studied before and after the administration of pilocarpine and, in some subjects, again after its withdrawal.

Visual acuity. Standard Snellen chart at $6 \mathrm{~m}$ (with distance correction if required).

Anterior chamber depth (Haag-Streit pachometer and slit-image photography).

Anterior chamber cross-section area (slit-image photography, from which anterior chamber volume was calculated).

Corneal thickness (Haag-Streit pachometer).

Applanation tension (Goldmann).

Pupil diameter (pupillometer).

Lens anterior radius (slit-image photography).

The photographic method described by Jones and Maurice (1963) for measuring the volume of the anterior chamber by means of attachments to the Haag-Streit 900 slit-lamp was later modified (Brown, 1973a) to produce an improved image of the anterior chamber; measurements were then made from the photographs using a Perspex grid (Figs $I$ and 2). The modified technique was used in the present study for measuring the depth and for calculating the volume of the anterior chamber.

The radius of curvature of the anterior surface of the lens was measured in only ro eyes in which the lens was sufficiently well recorded in the photographs when the pupil was miosed. The radii were measured from the projected images using the mirror technique as 


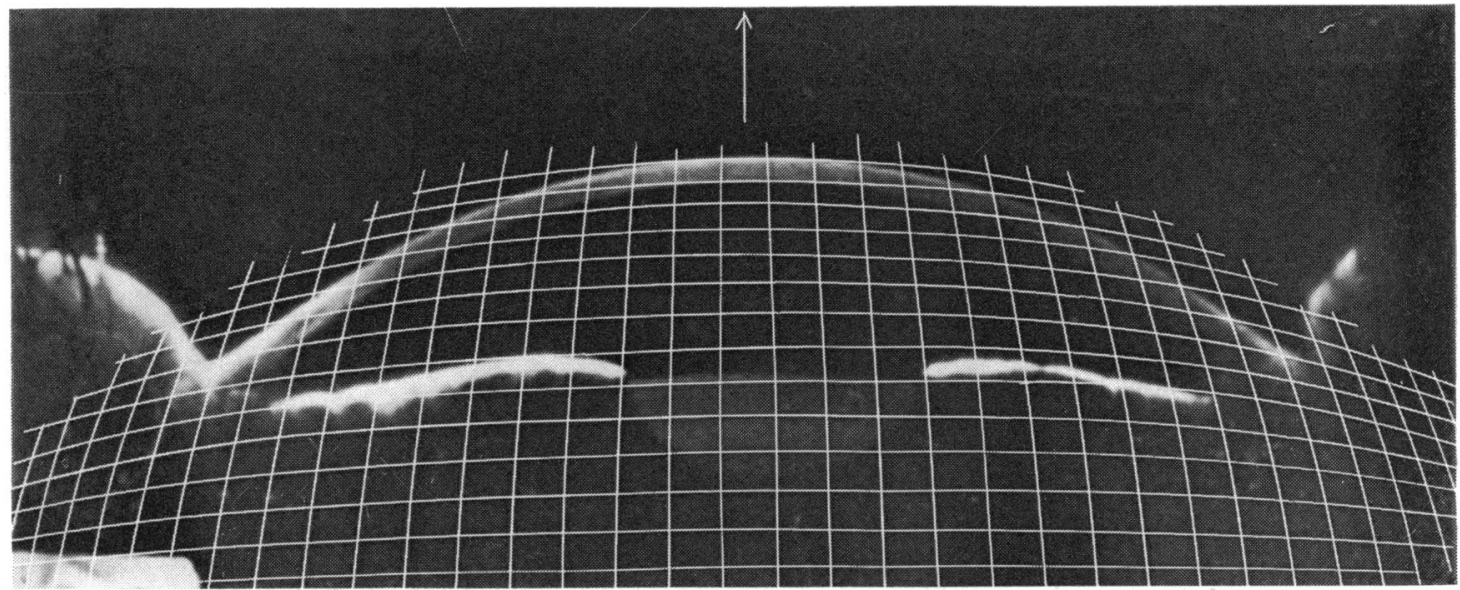

(I)

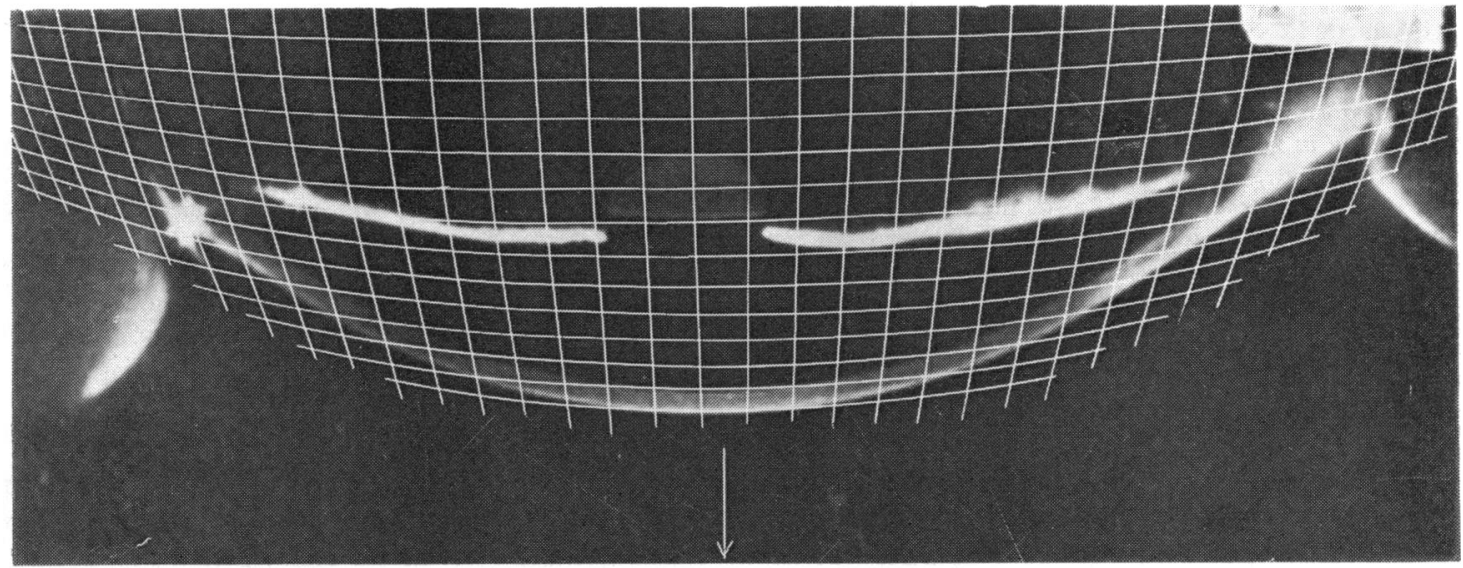

(2)

FIGS I and 2 Anterior segment photographs taken before (Fig. I) and after (Fig. 2) pilocarpine. Note distance between posterior surface of cornea and anterior surface of lens (3.1 $\mathrm{mm}$ before and $2.7 \mathrm{~mm}$ after administration)

described by Fisher (197I) and modified by Brown (1973a) to allow for corneal refraction.

\section{Results}

CHANGES IN CORNEA, INTRAOCULAR PRESSURE, AND ANTERIOR CHAMBER DEPTH WITH PILOCARPINE (TABLE I)

There was no change in corneal thickness, but there was a significant reduction in the radii of curvature of both the horizontal and vertical meridia of the corneae with pilocarpine, which correlated well with the reduction in intraocular pressure $(r=0.64)$. There was also a significant shallowing of the anterior chamber.

\section{CHANGES IN VISUAL ACUITY WITH PILOCARPINE}

The visual acuity with pilocarpine in 102 glaucomatous eyes deteriorated in 78 eyes, improved in six, and was
Table I Changes in cornea, intraocular pressure, and anterior chamber depth with pilocarpine

\begin{tabular}{|c|c|c|c|}
\hline & \multicolumn{3}{|c|}{$\begin{array}{l}\text { Mean values from } 55 \text { eyes } \\
\text { with glaucoma }\end{array}$} \\
\hline & $\begin{array}{l}\text { Without } \\
\text { pilo- } \\
\text { carpine }\end{array}$ & $\begin{array}{l}\text { With } \\
\text { pilo- } \\
\text { carpine }\end{array}$ & Difference \\
\hline $\begin{array}{l}\text { Corneal thickness }(\mathrm{mm}) \\
\text { Horizontal meridia }\end{array}$ & 0.56 & 0.56 & ० \\
\hline$(\mathrm{mm})$ & $7 \cdot 86$ & $7 \cdot 78$ & $-0.08^{*}$ \\
\hline Vertical meridia $(\mathrm{mm})$ & $7 \cdot 90$ & $7 \cdot 81$ & $-0.09^{*}$ \\
\hline $\begin{array}{l}\text { Intraocular pressure } \\
(\mathrm{mmHg}) \\
\text { AC depth }(\mathrm{mm})\end{array}$ & $\begin{array}{l}30 \cdot 7 \\
2 \cdot 72\end{array}$ & $\begin{array}{l}19 \cdot 6 \\
2 \cdot 6 I\end{array}$ & $\begin{array}{l}-I I \cdot I^{*} \\
-O \cdot I I^{*}\end{array}$ \\
\hline
\end{tabular}

*Significant $P=>0.05$ 
unchanged in the remainder. In those eyes in which the visual acuity deteriorated it fell from one to five lines on the Snellen chart. In all these eyes the visual acuity could be corrected to the previous value with the addition of minus spheres to the distance refraction. The correction needed varied from $-0.25 \mathrm{D}$ to $-1 \cdot 75 \mathrm{D}$ with a mean value of $0.95 \mathrm{D}$. Miosis occurred in all eyes but was evidently not the cause of the reduced visual acuity since this could be corrected with minus lenses.

\section{CHANGES IN ANTERIOR CHAMBER DIMENSIONS WITH PILOCARPINE (Table II)}

There was a highly significant reduction in anterior chamber depth, area, and calculated volume within 15 minutes $(P=<0.01)$; this increased up to 30 minutes, but it did not increase after 60 minutes. The anterior chamber volume was found to be well correlated with the anterior chamber depth as shown in Fig. 3.

CHANGES IN LENS RADIUS OF CURVATURE (Table III)

In all the lenses measured, the radius of curvature of the anterior surface became shorter with pilocarpine. The change in radius was highly significantly correlated $(r=0.84)$ with the degree of myopic change in refraction. The change in radius was also highly significantly correlated $(r=0.84)$ with the change in anterior chamber depth and inversely $r=0.84$ with the age of the subject.

Table II Changes in anterior chamber dimensions with pilocarpine

\begin{tabular}{|c|c|c|c|c|}
\hline & \multicolumn{4}{|c|}{ Mean values for 125 eyes } \\
\hline & \multirow{2}{*}{$\begin{array}{l}\text { Without } \\
\text { pilo- } \\
\text { carpine }\end{array}$} & \multicolumn{3}{|c|}{ After pilocarpine } \\
\hline & & I 5 min & $30 \min$ & $60 \min$ \\
\hline AC depth (mm) & $2 \cdot 82$ & $2 \cdot 38$ & $2 \cdot 27$ & $2 \cdot 25$ \\
\hline Area $\left(\mathrm{mm}^{2}\right)$ & $21 \cdot 0$ & $16 \cdot 5$ & $15 \cdot 8$ & 15.7 \\
\hline Volume $(\mu \mathrm{l})$ & I 55 & 117 & 112 & I I I \\
\hline
\end{tabular}

Table III Radius of curvature of the anterior lens surface before and after pilocarpine

\begin{tabular}{|c|c|c|c|}
\hline & $\begin{array}{l}\text { Age } \\
\text { (years) }\end{array}$ & $\begin{array}{l}\text { Before } \\
\text { pilocarpine } \\
(\mathrm{mm})\end{array}$ & $\begin{array}{l}\text { After } \\
\text { pilocarpine } \\
(\mathrm{mm})\end{array}$ \\
\hline $\mathbf{I}$ & 73 & $12 \cdot 5$ & $9 \cdot 3$ \\
\hline 2 & 39 & 14.8 & $9 \cdot 3$ \\
\hline 3 & 68 & 13.5 & 10.9 \\
\hline 4 & 74 & I I'2 & 10.6 \\
\hline 5 & 45 & $12 \cdot 7$ & 9.7 \\
\hline 6 & 73 & 10.1 & $8 \cdot 1$ \\
\hline 7 & 77 & $12 \cdot 8$ & $9 \cdot 4$ \\
\hline 8 & 75 & I I 8 & II'O \\
\hline 9 & 65 & 13.8 & $9 \cdot 4$ \\
\hline 10 & 68 & I I 9 & $8 \cdot 2$ \\
\hline
\end{tabular}

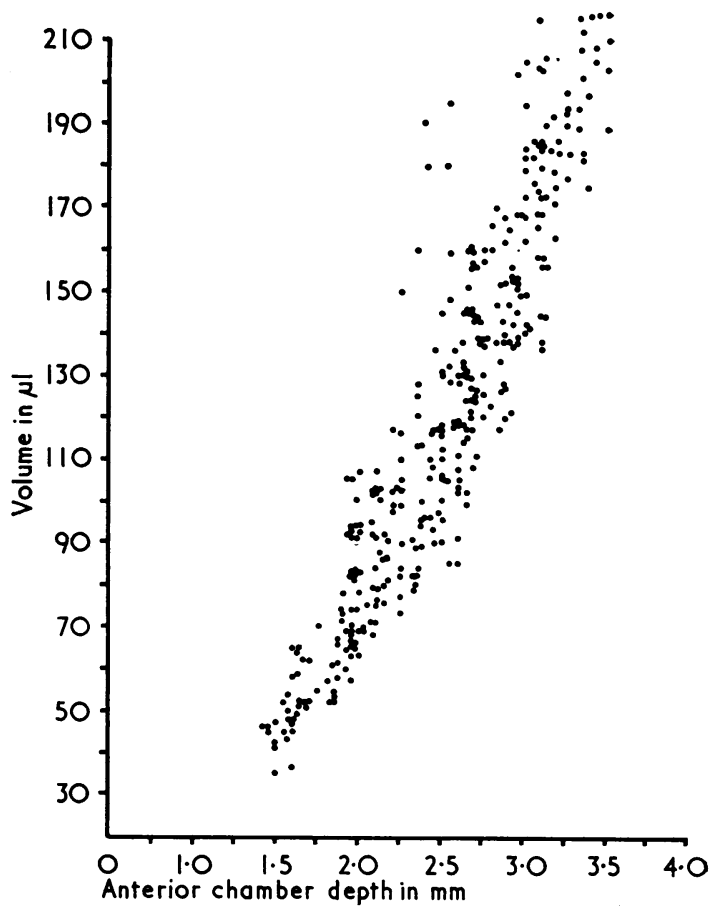

FIG. 3 Correlation between volume and depth of anterior chamber

\section{Discussion}

This decrease in the depth of the anterior chamber as a result of pilocarpine confirms earlier reports (Heim, I94I; Rosengren, I950; Törnqvist, 1956; Bleeker, 1960; Abramson and others, 1972).

The change in visual acuity for distance appears to be accounted for by a myopic shift since the visual acuity could be corrected to pretreatment levels, in all patients in whom it was reduced, by the addition of minus lenses.

The small reduction in radius of curvature of the cornea after pilocarpine had been instilled is likely to be related directly to the fall in intraocular pressure. The reduction in radius alone would produce a myopic shift, but it is likely to be outweighed by an accompanying reduction in axial length of the globe. It has previously been shown (Poinoosawmy and Roth, 1974) that raised intraocular pressure is associated with an increase in the radius of curvature of the cornea and with a myopic shift which appears to be due to increased axial length of the globe. Thus the small changes in external dimensions of the eye resulting from reduced intraocular pressure would probably result in a net hypermetropic shift. But since the overall change is towards myopia, the changes in the axial length must be outweighed by other 
changes in the eye and it is likely that changes in the lens are responsible. A forward movement of the anterior pole of the lens is demonstrated in all subjects in whom there is a myopic shift and ro of these subjects in whom the radius of curvature of the anterior lens surface could be measured showed a reduction in radius. The present study does not measure the sagittal width of the position of the posterior pole of the lens.

It seems likely that the changes now observed in the lens of the eyes are the same as those occurring in accommodation in which the increase in sagittal width of the lens is associated with a greater forward movement of the anterior pole than backward movement of the posterior pole, so that there is a forward movement of the lens centre (Coleman, 1970; Brown, 1973b). Similar changes have also been demonstrated by ultrasound after pilocarpine administration (Abramson, 1972).

Forward movement of the lens increases its effectiveness, but in accommodation it is mainly the change in lens radius of curvature which is responsible for producing near focus (Brown, 1973b). It is likely that the reduced radius of curvature of the lens is the main factor in producing myopia in our subjects.

It appears that the myopia induced by pilocarpine is due to the action on the ciliary body causing it to contract and to produce the lens changes normally seen in accommodation. The myopic changes were least in the older subjects as could be expected from the presbyopic reduction in accommodation.

Another interesting observation in the present study is the correlation between the depth and volume of the anterior chamber, which was found to be highly significant. Jones and Maurice (1966) obtained a value of $175 \pm 30 \mu$ for the volume of the anterior chamber in normal subjects. The mean volume in the pretreated group in our study, which included both normal and glaucomatous eyes, was approximately $154.62 \pm 7.0221 \mu 1$, and the slight difference could well be due to the inclusion of eyes with shallow anterior chambers.

\section{Summary}

The effect of pilocarpine on visual acuity and on the dimensions of the cornea, anterior chamber, and lens were studied in two groups of subjects. Significant changes in ocular tension, corneal curvature, anterior chamber depth, and lens anterior radius were found in a group of 55 glaucomatous eyes as a result of pilocarpine treatment, but there was no change in corneal thickness. Out of 102 glaucomatous eyes 78 became relatively myopic, and this appears to be due to changes in the dimensions of the lens of the eye similar to those occurring in accommodation, as a result of the effect of the drug on the ciliary muscle.

The effect of pilocarpine on anterior chamber depth, area, and volume was studied in 125 eyes using a photographic method, and a significant reduction in the dimensions of the anterior chamber was observed as a result of the administration of pilocarpine. A significant correlation between depth and volume was also noted and the implications of this are discussed.

We thank Professor J. Gloster for allowing us to examine his patients in the Glaucoma Clinic of the Institute of Ophthalmology and Professor E. S. Perkins for useful discussions.

We acknowledge the help received from Mr Brian Augier for computing the results, and from Mrs Fiona Dolamore for secretarial assistance.

\section{References}

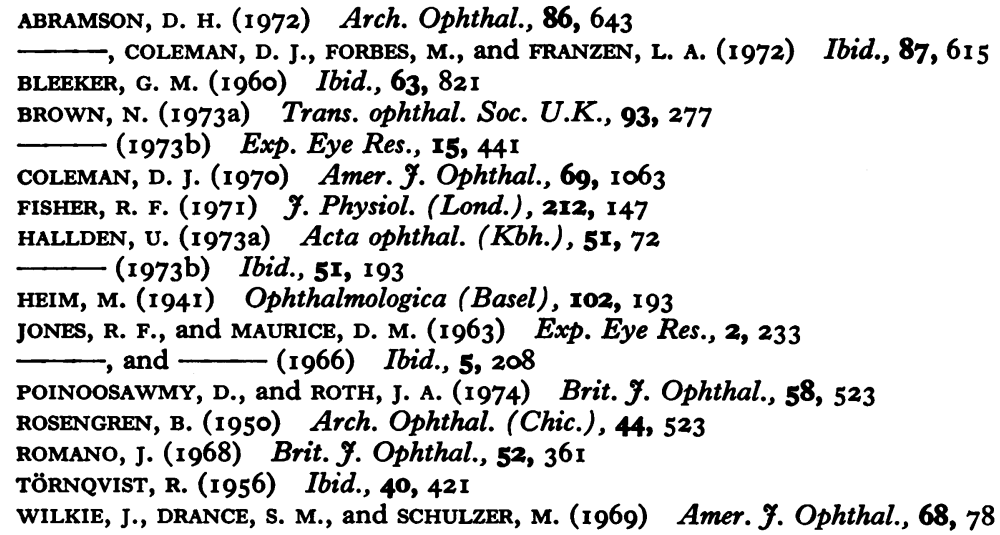

